Reserve-Growth Assessment Project

\title{
Assessment of Potential Additions to Conventional Oil and Gas Resources of the World (Outside the United States) from Reserve Growth, 2012
}

The U.S. Geological Survey estimated volumes of technically recoverable, conventional petroleum resources resulting from reserve growth for discovered fields outside the United States that have reported in-place oil and gas volumes of 500 million barrels of oil equivalent or greater. The mean volumes were estimated at 665 billion barrels of crude oil, 1,429 trillion cubic feet of natural gas, and 16 billion barrels of natural gas liquids. These volumes constitute a significant portion of the world's oil and gas resources.

\section{Introduction}

The U.S. Geological Survey (USGS) estimated volumes of technically recoverable, conventional oil and gas resources that have the potential to be added to reserves (called "reserve growth" hereafter) in discovered oil and gas fields of the world outside the United States with reported in-place oil and gas volumes of 500 million barrels of oil equivalent (MMBOE) [0.5 billion barrels (BB) of oil or 3 trillion cubic feet (TCF) of gas] or greater. Unlike past assessments of reserve growth that relied on statistical extrapolations of growth trends, this methodology includes detailed analysis of geology and engineering practices observed in developed fields. Because of the paucity of data for many fields outside the United States, data acquired from U.S. fields undergoing reserve growth were used as analogs in this study. The assessment was based on published geologic information, data from commercial sources on petroleum volumes of oil and gas wells and fields, and field production records.

\section{Methodology}

The primary data used to estimate reserve growth are original in-place volumes and recovery factors. Studies of 68 large oil accumulations and 2 large gas accumulations in the United States provided probability distributions for uncertainty of original (initial) in-place volumes, as well as a probability distribution of oil recovery factors. These distributions were used as analogs for large fields outside the United States. The assessment methodology used to assess reserve growth of U.S. fields is described in Klett and others (2011).

Probability distributions of original in-place volumes for U.S. fields were assigned to reported original in-place volumes for fields outside the United States. Probability distributions of recovery factors for the 68 U.S. oil accumulations were assumed for oil fields outside the United States. A uniform probability distribution of the mean reported recovery factor of nonassociated gas fields outside the United States was assumed for recovery factors in gas fields. The original in-place and recovery factor distributions assigned to a given field were statistically combined (multiplied) by Monte Carlo simulation to provide a probability distribution of estimated reserve growth.

Reserve growth of coproducts was calculated by statistical combination (multiplication) using Monte Carlo simulation of the reserve growth of the primary commodity (oil or gas) with the volumetric coproduct ratios. The growth of associated and dissolved gas, and natural gas liquids in the associated and dissolved gas, was calculated for oil fields. The growth of oil plus natural gas liquids (total liquids) was calculated for nonassociated gas fields. Coproduct reserve growth was not estimated for fields having unreported coproduct volumes.

Reserve growth was estimated for fields having reported original in-place oil or gas of $500 \mathrm{MMBOE}$ or greater. Continuous oil and gas (unconventional) accumulations and tar sands were excluded. The reserve growth estimated in this study accounts for about 80 percent of the potential reserve growth of the world outside the United States; the other 20 percent is in fields with in-place volumes smaller than 500 MMBOE. Large fields were chosen

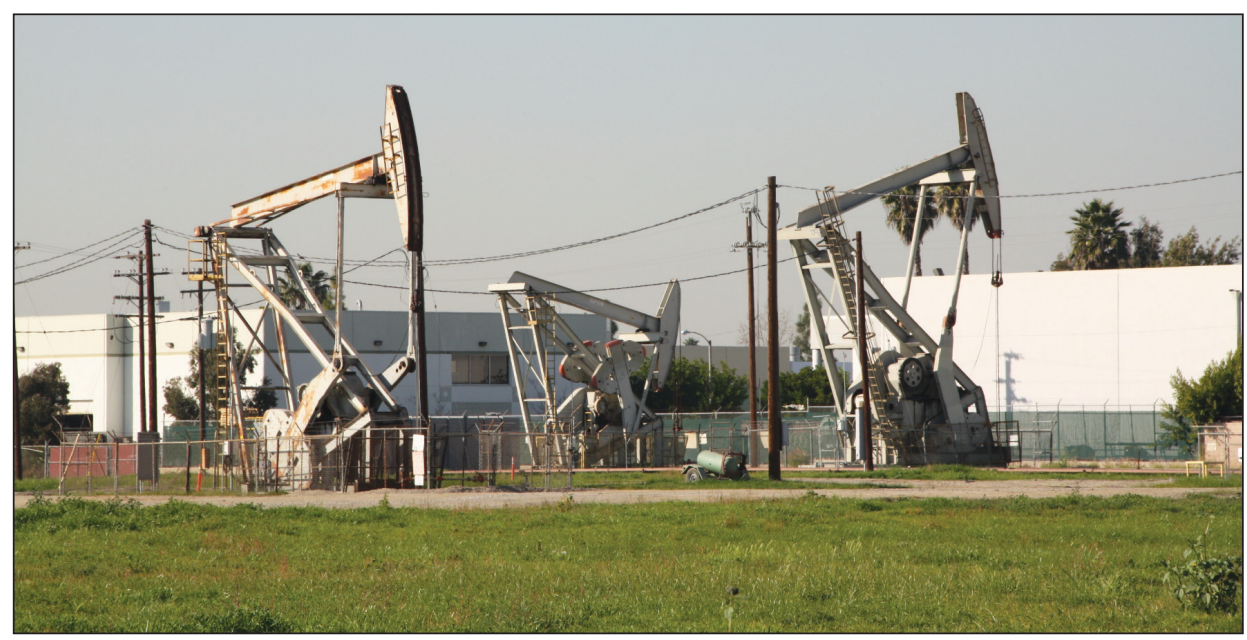

Pump jacks photograph by Ken Takahashi, U.S. Geological Survey, January 2011. 
Table 1. Estimated reserve growth of discovered fields outside the United States with reported in-place volumes of 500 million barrels of oil equivalent or greater (technically recoverable, conventional petroleum resources).

[MMBOE, million barrels of oil equivalent; BB, billion barrels; TCF, trillion cubic feet. For gas fields, all liquids are included under the natural gas liquids (NGL) category. F95 denotes a 95-percent chance of at least the amount tabulated. Other fractiles are defined similarly. Negative values indicate the possibility that reported reserves could decrease. Gray shading indicates not applicable]

\begin{tabular}{|c|c|c|c|c|c|c|c|c|c|c|c|c|c|c|}
\hline \multirow{3}{*}{$\begin{array}{l}\text { World (outside the United States): } \\
\text { Discovered fields with in-place } \\
\text { volumes of } 500 \mathrm{MMBOE} \\
\text { or greater }\end{array}$} & \multirow{3}{*}{$\begin{array}{l}\text { Field } \\
\text { type }\end{array}$} & \multirow{3}{*}{$\begin{array}{c}\text { Number } \\
\text { of } \\
\text { fields }\end{array}$} & \multicolumn{12}{|c|}{ Estimated reserve growth } \\
\hline & & & \multicolumn{4}{|c|}{ Oil (BB) } & \multicolumn{4}{|c|}{ Gas (TCF) } & \multicolumn{4}{|c|}{ NGL (BB) } \\
\hline & & & F95 & F50 & F5 & Mean & F95 & F50 & F5 & Mean & F95 & F50 & F5 & Mean \\
\hline \multirow{2}{*}{ Reserve growth by commodity } & Oil & 1,467 & 329 & 598 & 1,205 & 665 & 592 & 956 & 1,766 & 1,043 & -16 & -2 & 18 & -1 \\
\hline & Gas & 347 & & & & & -469 & 210 & 1,781 & 386 & -14 & 11 & 65 & 17 \\
\hline Total reserve growth & & 1,814 & & & & 665 & & & & 1,429 & & & & 16 \\
\hline
\end{tabular}

for this study because they are most likely to experience reserve growth, and their oil and gas volume data are relatively well reported and accurate. In addition, most of the world's in-place volumes and reserves, outside the United States, reside in 1,814 fields having reported original in-place oil or gas of $500 \mathrm{MMBOE}$ or greater. Approximately 85 percent of the world's original in-place oil outside the United States resides in 1,467 oil fields (about 9 percent of the total number of oil fields). Approximately 79 percent of the original in-place nonassociated gas resides in 347 gas fields (about 3 percent of the total number of nonassociated gas fields).

\section{Assessment Results}

Estimates of volumes of technically recoverable, conventional oil and gas resources of the world outside the United States from reserve growth are listed in table 1. No attempt was made to estimate economically recoverable resources. The estimated mean volumes of oil and gas are about $665 \mathrm{BB}$ of crude oil, 1,429 TCF of natural gas (1,043 TCF of associated and dissolved natural gas and 386 TCF of nonassociated natural gas), and $16 \mathrm{BB}$ of natural gas liquids $(-1 \mathrm{BB}$ of natural gas liquids in oil accumulations and $17 \mathrm{BB}$ of total liquids in nonassociated gas accumulations). Negative values indicate the possibility that reported reserves could decrease rather than increase (growth).

\section{Reference Cited}

Klett, T.R., Attanasi, E.D., Charpentier, R.R., Cook, T.A., Freeman, P.A., Gautier, D.L., Le, P.A., Ryder, R.T., Schenk, C.J., Tennyson, M.E., and Verma, M.K., 2011, New U.S. Geological Survey method for the assessment of reserve growth: U.S. Geological Survey Scientific Investigations Report 2011-5163, 9 p., available at http://pubs.usgs.gov/sir/2011/5163/

\section{For Further Information}

Supporting geologic studies of total petroleum systems and assessment units, and reports on the methodology used in this assessment of the world outside the United States, as well as the assessment results, are available at the USGS Energy website: http://energy.usgs.gov/.

\section{Reserve Growth Assessment Team}

Timothy R. Klett (tklett@usgs.gov), Troy A. Cook, Ronald R. Charpentier, Marilyn E. Tennyson, Emil D. Attanasi, Phil A. Freeman, Robert T. Ryder, Donald L. Gautier, Mahendra K. Verma, Phuong A. Le, Christopher J. Schenk. 